\title{
A New Clonal Propagation Protocol Develops Quality Root Systems in Chestnut
}

\author{
Patrícia Fernandes ${ }^{1,2}$, Sara Tedesco ${ }^{1,3}{ }^{(0)}$, Inês Vieira da Silva ${ }^{1,4,5}$ () , Carmen Santos ${ }^{1,3} \mathbb{C}^{1}$, \\ Helena Machado ${ }^{1}$ and Rita Lourenço Costa ${ }^{1,6, * \mathbb{D}}$ \\ 1 Instituto Nacional de Investigação Agrária e Veterinária I.P., Avenida da República, \\ 2780-159 Oeiras, Portugal; patricia.fernandes@iniav.pt (P.F.); sara.tedesco@itqb.unl.pt (S.T.); \\ imsilva1@campus.ul.pt (I.V.d.S.); css@itqb.unl.pt (C.S.); helena.machado@iniav.pt (H.M.) \\ 2 Green-It Bioresources for Sustainability, ITQB NOVA, Av. Da República, 2780-157 Oeiras, Portugal \\ 3 Instituto de Tecnologia Química e Biológica António Xavier, Universidade Nova de Lisboa, \\ Av. Da República, 2780-157 Oeiras, Portugal \\ 4 Instituto de Investigação do Medicamento (iMed.ULisboa), Faculdade de Farmácia, Universidade de Lisboa, \\ 1649-003 Lisboa, Portugal \\ 5 Departamento de Bioquímica e Biologia Humana, Faculdade de Farmácia, Universidade de Lisboa, \\ 1649-003 Lisboa, Portugal \\ 6 Centro de Estudos Florestais, Instituto Superior de Agronomia, Universidade de Lisboa, Tapada da Ajuda, \\ 1349-017 Lisboa, Portugal \\ * Correspondence: rita.lcosta@iniav.pt; Tel.: +351-919073379
}

Received: 21 June 2020; Accepted: 26 July 2020; Published: 29 July 2020

check for updates

\begin{abstract}
There is, at the present time, a great demand for chestnut rootstocks with improved resistance to Phytophthora cinnamomi Rands in the nurseries. New genotypes are emerging from European chestnut breeding programs and the production of thriving plants to restore old orchards with low yields due to a high incidence of diseases, namely root rot, is necessary. Micropropagation is a useful technique for clonal propagation. Nevertheless, in vitro culture propagation is genotype-dependent. Consequently, the existing protocols may demonstrate poor reproducibility and low efficacy. Thus, the need to contribute to the development of new micropropagation protocols suitable for large production of emerging genotypes. As a contribution to fill this gap, a three-step protocol was developed by using new combinations of Murashige \& Skoog, Woody Plant, and adapted modified Melin-Norkrans media in different stages of the propagation process. About $90 \%$ of shoots were rooted, and after three months of acclimatization, $85 \%$ of these plants survived and were capable of continuous growth in the field. Currently, this protocol is being used in the production of several hybrid genotypes (with improved resistance to $P$. cinnamomi), selected from our ongoing breeding program and also in Castanea sativa Mill. and Castanea crenata Siebold and Zucc. species.
\end{abstract}

Keywords: axillary shoot proliferation; Castanea hybrids; rooting; rootstocks; tissue culture

\section{Introduction}

The European chestnut (Castanea sativa Mill.) is a multipurpose tree, having a significant economic interest for nut and wood production. Chestnut cultivars have been maintained by clonal propagation using agronomic techniques such as rooting of cuttings. However, rooting of mature chestnut tissue has proven to be a very difficult process [1,2]. Traditionally, chestnut cultivars were propagated by grafting onto seedlings of C. sativa [3]. However, due to the high susceptibility of this species to the oomycete Phytophthora cinnamomi Rands (the causal agent of root rot/ink disease) [4], the use of grafting has become compromised. Hybrid clones of C. sativa with Castanea crenata Siebold and Zucc. or Castanea mollissima Blume-the Asian species resistant to P. cinnamomi-are recommended as resistant 
rootstocks for plantations in affected areas [3,5]. The available genotypes in the European market are from breeding programs from the 20th century $[3,6]$. Changes projected in the distribution of the pathogen due to climate change [7] may lead to differences in disease expression (due to the emergence of new strains and hosts). This creates a demand for new chestnut material, better adapted to the current and predicted future climatic conditions. Therefore, new genotypes with improved resistance to $P$. cinnamomi were selected from the Portuguese chestnut breeding program, initiated in $2006[8,9]$.

Orchards need to be renewed and for that, it is essential to have numerous thriving plants ready for field plantation. Micropropagation has proven to be an essential tool to overcome the production difficulties of adult selected trees, including chestnut species and their hybrids [10-14]. Micropropagated plants require acclimatization to ex vitro conditions. Problems with root induction and the physiological status of the shoot, during and after the rooting process, have made acclimatization the most critical step in the culture of mature chestnut materials $[15,16]$. Juvenile physiological characteristics of the shoot are related to the chestnuts' ability to root $[17,18]$. Meaning that, before rooting, the shoots need to be capable of achieving exponential growth. This can be accomplished with optimal in vitro culture conditions, mainly through the culture medium. Chestnut species and hybrids have already been effectively micropropagated and rooted $[5,15,19-21]$. However, since in vitro propagation is genotype-dependent, the selection of culture media and rooting steps remains an area of research. Thus, novel and optimized protocols are urgently needed for emerging genotypes.

The goal of this work was to develop a new protocol for the propagation of chestnut from the laboratory to the field. For this purpose, one P. cinnamomi-resistant chestnut hybrid [9] was used as a case study, demonstrating the best medium to induce the optimal juvenile state of the shoots before rooting and proceeded to the test of an innovative in vitro rooting protocol that enables the development of healthy roots in three weeks.

\section{Materials and Methods}

\subsection{Plant Material and Culture Conditions}

A well-characterized P. cinnamomi-resistant hybrid (C. sativa $\times$ C. mollissima, genotype SM904) $[9,22]$ was selected as plant material. Shoot cultures were previously established in vitro from axillary bud tissue collected from the mother plant. The disinfection process started by placing the axillary buds in 70\% (v/v) ethanol for $20 \mathrm{sec}$, followed by a wash with Tween-20 1\% (v/v). After 3 min the buds were transferred to a $50 \%(v / v)$ solution of commercial bleach, where they remained for $5 \mathrm{~min}$ with vigorous stirring. After this step, the explants were washed in sterile distilled water for $5 \mathrm{~min}$ (this was repeated twice). After disinfection, the explants were placed in individual test tubes $(15 \times 2.2 \mathrm{~cm})$ with $15 \mathrm{~mL}$ of Murashige \& Skoog medium [23] (half concentration of $\mathrm{NH}_{4} \mathrm{NO}_{3}$ and $\mathrm{KNO}_{3}$ ) supplemented with $1 \mathrm{mg} / \mathrm{L}$ benzyladenine (BA), $100 \mathrm{mg} / \mathrm{L}$ ascorbic acid, $30 \mathrm{~g} / \mathrm{L}$ sucrose and $8 \mathrm{~g} / \mathrm{L}$ agar. The $\mathrm{pH}$ was adjusted to $5.6-5.8$ before autoclaving at $121^{\circ} \mathrm{C}$ and 15 psi for $20 \mathrm{~min}$.

After the establishment, cultures were transferred and maintained in Eco2Box with green filter (oval modal $80 \mathrm{~mm} \mathrm{H}$; Duchefa Biochemie, Haarlem, The Netherlands) on $100 \mathrm{~mL}$ of the same medium described above with BA concentration reduced to $0.1 \mathrm{mg} / \mathrm{L}$ (henceforth referred as MSB medium). Fifteen shoots were placed in each container and maintained at $23{ }^{\circ} \mathrm{C}$ under a 16 -hour light (20-50 $\left.\mu \mathrm{mol} \mathrm{m}{ }^{-2} \mathrm{~s}^{-1}\right)$ photoperiod. Subcultures were made every six weeks.

\subsection{Elongation}

After six weeks in culture, healthy shoots (about $3 \mathrm{~cm}$ tall) were transferred to the elongation phase. Two elongation media were tested: (1) the maintenance MSB medium; (2) full-strength woody plant medium (WPM) [24], with $100 \mathrm{mg} / \mathrm{L}$ of ascorbic acid, $30 \mathrm{~g} / \mathrm{L}$ sucrose and supplemented with $0.1 \mathrm{mg} / \mathrm{L}$ of zeatin and $8 \mathrm{~g} / \mathrm{L}$ agar (hereinafter referred as WPMZ medium). The $\mathrm{pH}$, containers, autoclave, and culture conditions were the same as described in the previous section. 
After 6 weeks the development of shoots micropropagated in both media was compared by measuring the length of the shoots $(\mathrm{mm})$, number of leaves per shoot, biggest leaf length and width $(\mathrm{mm})$, dry mass (mg) and number of new shoots from the base of the initial explant. Forty-five shoots of each treatment were analyzed.

\subsection{Rooting and Acclimatization}

Before rooting, shoots elongated in MSB and WPMZ media were subcultured in the pre-rooting medium. The basal callus was removed, and shoots were placed on a modified MSB medium, free of plant growth regulators (PGR) and with $3 \mathrm{~g} / \mathrm{L}$ activated charcoal. The $\mathrm{pH}$, containers, autoclave, and culture conditions are the same as described in Section 2.1. After seven days in the pre-rooting medium, the cut ends were excised (about 1-2 mm, just enough to renew the surface) and dipped in a filter-sterilized $1 \mathrm{~g} / \mathrm{L}$ indole-3-butyric acid (IBA) aqueous solution, at a depth of $0.5 \mathrm{~cm}$ for $1 \mathrm{~min}$. This was performed in a laminar flow cabinet.

For root development shoots were submitted to two different in vitro rooting conditions: treatment with an adapted modified Melin-Norkrans (MMN) [25] liquid medium and the control condition, using water. In more detail, SteriVent containers (High model; Duchefa Biochemie, Haarlem, The Netherlands) were filled with $300 \mathrm{~mL}$ of perlite:vermiculite (1:1) substrate mixture, soaked with $200 \mathrm{~mL}$ of (1) adapted MMN liquid medium, substituting glucose for sucrose $\left(250 \mathrm{mg}\left(\mathrm{NH}_{4}\right)_{2} \mathrm{HPO}_{4}\right.$, $150 \mathrm{mg} \mathrm{MgSO}_{4} .7 \mathrm{H}_{2} \mathrm{O}, 500 \mathrm{mg} \mathrm{KH} \mathrm{PO}_{4}, 25 \mathrm{mg} \mathrm{NaCl}, 50 \mathrm{mg} \mathrm{CaCl}$, $1.2 \mathrm{~mL} \mathrm{FeCl} 3$ (1\% solution), $0.1 \mathrm{mg}$ Thiamine $\mathrm{HCl}, 10 \mathrm{~g}$ sucrose and $3 \mathrm{~g}$ malt extract; distilled water to $1 \mathrm{~L} ; \mathrm{pH}$ adjusted to 5.6-5.8 before autoclaving at $121^{\circ} \mathrm{C}$ and $15 \mathrm{psi}$, for $20 \mathrm{~min}$ ); (2) $200 \mathrm{~mL}$ of sterile distilled water, as control. Twenty shoots were placed per container and cultures were maintained at $24 \pm 1{ }^{\circ} \mathrm{C}$ under a 16-hour light (20-50 $\left.\mu \mathrm{mol} \mathrm{m} \mathrm{m}^{-2} \mathrm{~s}^{-1}\right)$ photoperiod for three weeks. Three replicates of twenty shoots each were analyzed per treatment for the following parameters: root induction (percentage of rooted shoots), branched roots (percentage of rooted shoots with secondary roots) and number of roots per rooted shoot.

Plants rooted with MMN medium were transferred to peat: perlite: vermiculite (1:1:1) mixture, acclimatized for two weeks in a controlled cabinet at $25 \pm 1{ }^{\circ} \mathrm{C}$ under a 16 -hour light $\left(20-50 \mu \mathrm{mol} \mathrm{m}^{-2} \mathrm{~s}^{-1}\right)$, with a relative humidity of $50 \%$, and then transferred to a greenhouse. After about three months, the acclimatization survival was registered and plants were transferred to field conditions (GPS coordinates: $39.347494,-7.395609$; field with sandy soil; $\mathrm{pH}=4.9$ ). Eight months after acclimatization they were dug out to visually access the root development.

\subsection{Statistical Analysis}

Data concerning the different parameters of growth during the elongation assays was presented as a pool of 45 shoots. The values of the 3 containers with 15 shoots were combined since no significant differences were found between containers. Data were analyzed and presented as mean \pm standard error (SE). A comparison of means for each of the different parameters of growth was accomplished by performing a Mann-Whitney nonparametric test $(p<0.05)$.

For the rooting tests, an analysis of variance (one-way ANOVA) was performed and significantly different means were identified by using the Tukey's test $(p<0.05)$. Data were listed as means \pm SE.

All tests were performed using GraphPad Prism version 5.00 for Windows, GraphPad Software, San Diego California USA, www.graphpad.com.

\section{Results}

\subsection{WPMZ Medium Leads to Improved Shoot Development}

The displayed differences in shoot development and morphology are shown in Figure 1. Excepting for the number of new shoots, all measured parameters were significantly higher in 
shoots elongated in WPMZ compared to shoots elongated in MSB. Figure 2 shows the development of the shoots after 6 weeks of culture in both media.

A

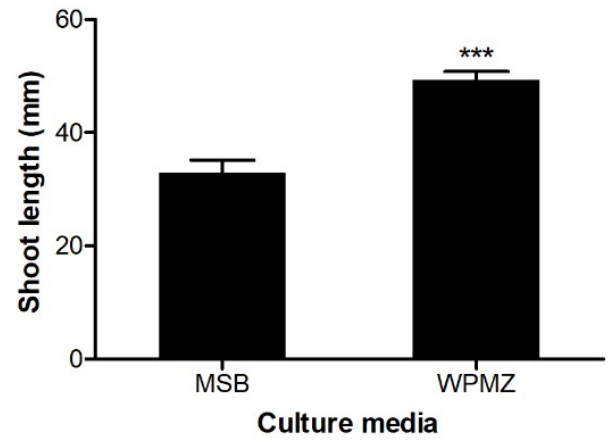

C
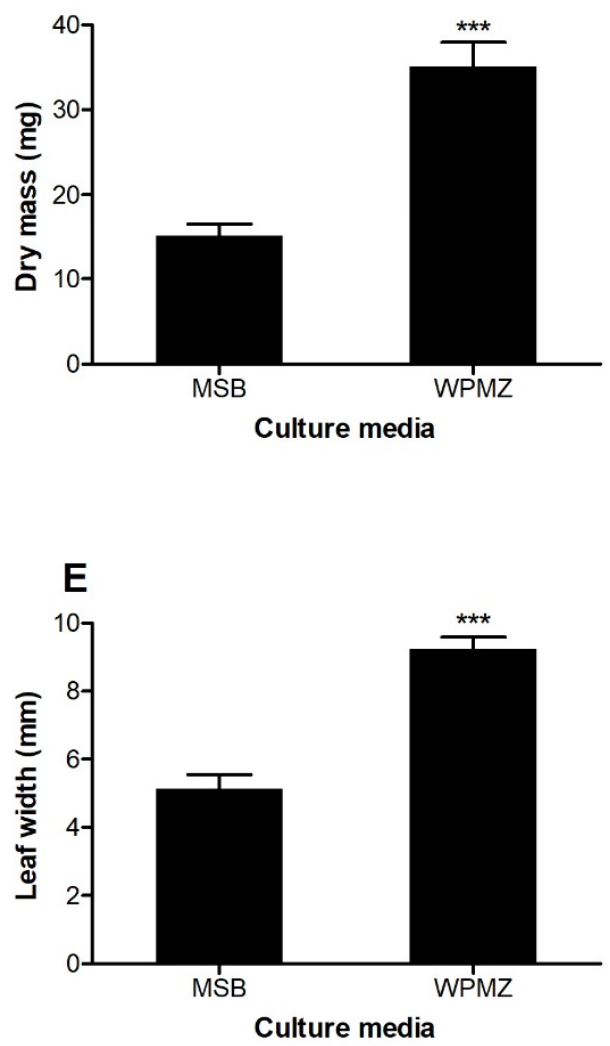
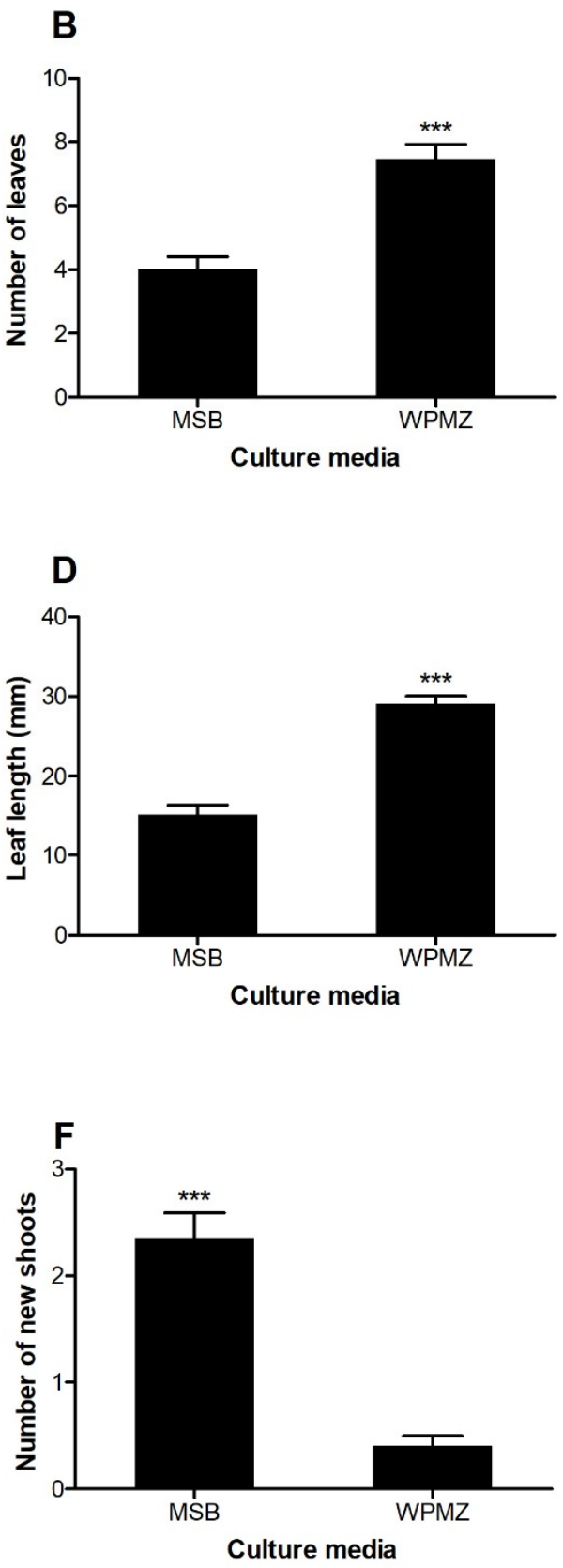

Figure 1. Effects of MSB and WPMZ media on the (A) shoot length, (B) number of leaves, (C) dry mass, (D) leaf length, (E) leaf width and (F) and number of new shoots of SM904 chestnut hybrid. Bars indicate standard error of the mean of 45 shoots. Significant differences are indicated with *** $(p<0.001$; Mann-Whitney test). 

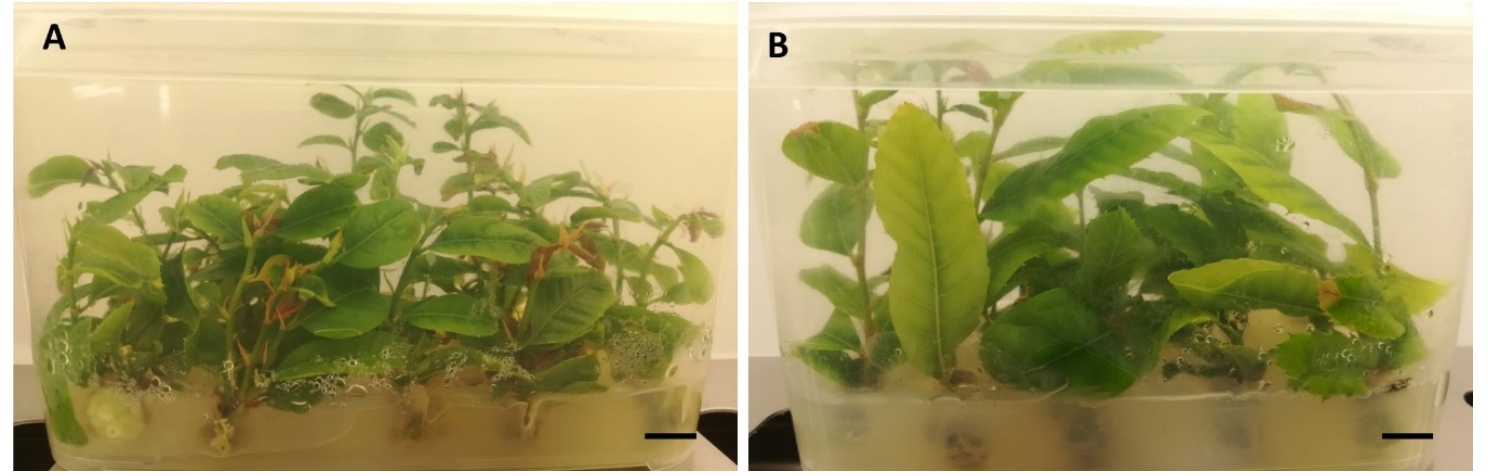

Figure 2. SM904 shoots after 6 weeks in (A) MSB and (B) WPMZ media. Bar $=1 \mathrm{~cm}$.

\subsection{MMN Liquid Medium Induces High Rooting Rates}

The response of the explants to the different conditions, three weeks after root induction with IBA, is shown in Figure 3.

A

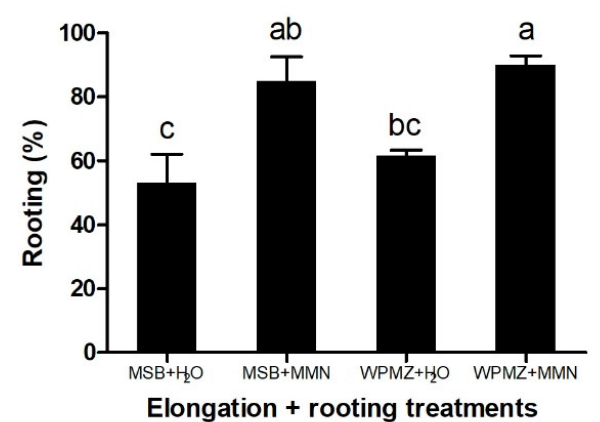

C

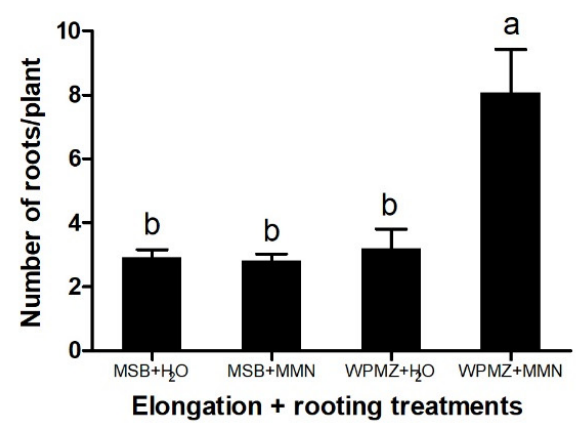

B

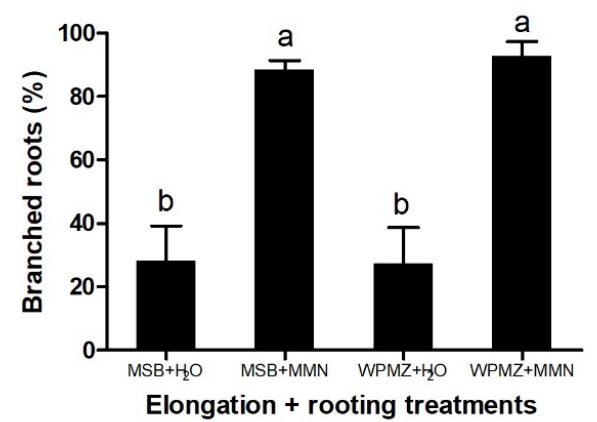

Elongation + rooting treatments

Figure 3. Effects of elongation and rooting media combinations (MSB $+\mathrm{H}_{2} \mathrm{O}, \mathrm{MSB}+\mathrm{MMN}$, WPMZ $+\mathrm{H}_{2} \mathrm{O}$, WPMZ + MMN) in (A) rooting percentage, (B) percentage of branched roots and (C) number of roots/plant. Data represent means of 3 replications of 20 shoots each. Bars indicate standard error. Means with different letters are significantly different (ANOVA and Tukey's test, $p<0.05)$.

The different treatments significantly affected the rooting rates $(\mathrm{F}=8.58 ; p=0.007)$. The use of MMN liquid medium induced higher percentages of rooting in shoots elongated in both MSB and WPMZ ( $85 \%$ and $90 \%$, respectively) in comparison with shoots rooted in the control conditions (Figure 3A). Other genotypes, elongated in WPMZ, also revealed similar percentages after rooting in MMN (Figure S1). The root branching also showed a significant improvement $(\mathrm{F}=18.91 ; p<0.001)$ in the MSB + MMN and WPMZ + MMN conditions ( $88.56 \%$ and $92.78 \%$, respectively) in comparison 
with only $28 \%$ in average from both ${ }_{\mathrm{d}} \mathrm{H}_{2} \mathrm{O}$ treatments (Figure 3B). A significant increase of the number of roots per plant $(\mathrm{F}=11.34 ; p=0.003)$ was observed in the shoots grown in WPMZ $+\mathrm{MMN}$ (8.08 roots/plant) when compared to the other treatments (3 roots/plant in average) (Figure 3C). Figure 4 presents examples of the different roots obtained during the assays.
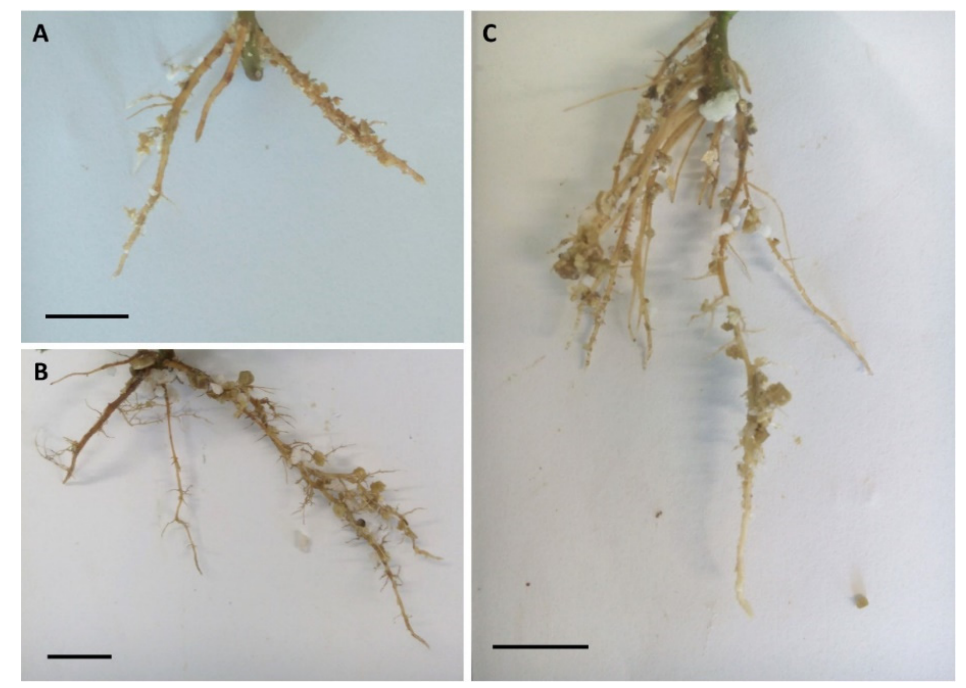

Figure 4. SM904 roots 3 weeks after induction with $1 \mathrm{~g} / \mathrm{L}$ indole-3-butyric acid (IBA) and development (A) in distilled water and (B,C) adapted MMN. Shoots were previously elongated in (A,B) MSB and (C) WPMZ. Bar $=1 \mathrm{~cm}$.

After three months of acclimatization, $40 \%$ and $85 \%$ of the plants rooted in MSB + MMN and WPMZ + MMN, respectively, survived. Figure 5A shows chestnut plants after eight months of acclimatization. These plants were then transferred to their permanent position with pruned roots and have shown an impressive development in the following two years (Figure 5B). Other hybrid genotypes, produced with WPMZ + MMN, were planted in a test field and the plantation success was about $90 \%$, with continuous development in the following two years (Figure S2).
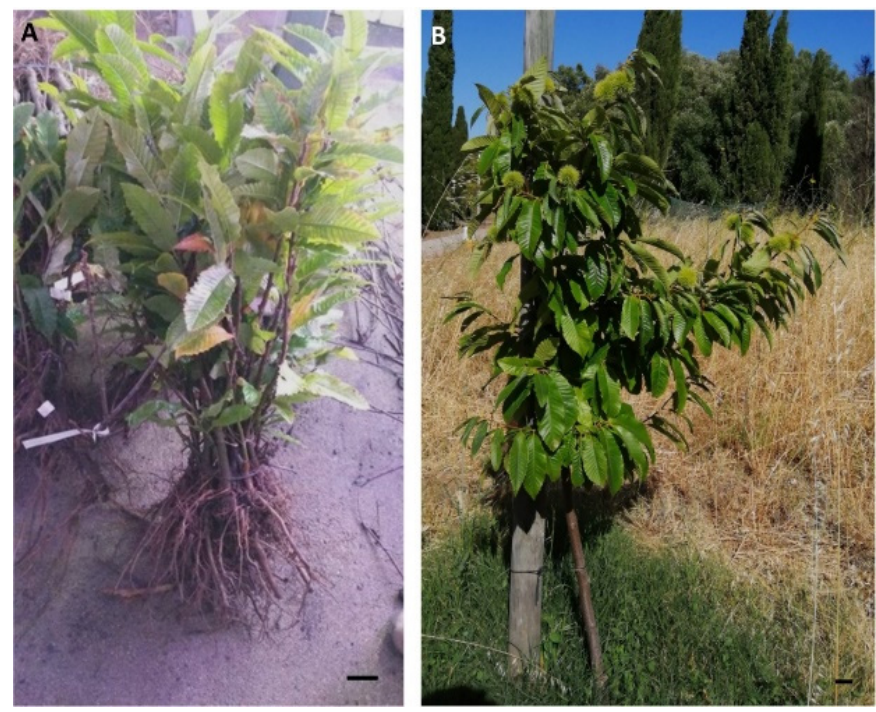

Figure 5. SM904 chestnut hybrids, rooted with adapted MMN liquid medium. (A) Plants eight months after acclimatization, with pruned roots before field plantation; (B) Plants with 2 years of growth in the field. Bars $=5 \mathrm{~cm}$. 


\section{Discussion}

For a long time, researchers have been developing protocols to overcome the recalcitrance of chestnut to clonal propagation and allow large scale production of selected genotypes [26]. This work describes a new propagation method that enables chestnut development from the laboratory to the orchard.

Elongation of shoots was tested in MSB (containing BA) and WPMZ (with zeatin) media. The use of MSB showed to be best for shoot multiplication since it promoted a higher number of new shoots than WPMZ. The combination of MS basal medium with BA has been proven to be effective for chestnut production by several researchers $[13,16,27]$, making it a common combination for chestnut in vitro multiplication. Nevertheless, the shoot length, number of leaves, biggest leaf length and width, and dry mass of shoots growing in WPMZ were higher than shoots cultured in MSB. Indeed, zeatin, combined with different basal media, has been considered the best PGR for micropropagation in other Castanea species, regarding shoot length and number of leaves [13]. This indicates that physiologically, shoots developed in the WPMZ medium may achieve an optimal juvenile state which is determinant for the production of a functional aerial shoot system, a key factor for successful acclimatization to ex vitro conditions [20]. Although the daily use of zeatin can be limiting due to its high cost, a single subculture in WPMZ should be enough to develop shoots in proper physiological conditions for rooting.

Activated charcoal is a common supplement in plant in vitro culture media, and its positive influences during the rooting process are well-documented [28]. This compound absorbs phenols [28], minimizes the carryover effects of PGRs when transferring shoots to medium without PGRs [29], and it also prevents callusing [30,31]. Before rooting, shoots were submitted to one short (seven days) subculture in a medium deprived of PGR with activated charcoal. This pre-rooting step works as a detoxification point to avoid carryover effects of zeatin and to avoid excessive callusing during the rooting process. Medium with activated charcoal has been proven to be successful for in vitro rooting of chestnut when used in combination with auxin [14,20]. To the best of our knowledge, it has never been used as an intermediate step in the rooting process of chestnut.

Efforts to overcome chestnut recalcitrance to rooting have created a body of knowledge describing a vast range of micropropagation techniques [13,16,20,32-34]. Gonçalves et al. tested MS semisolid media with concentrations of IBA from 1.5 to $5 \mathrm{mg} / \mathrm{L}$ in chestnut hybrids [16]. The best results were obtained with $5 \mathrm{mg} / \mathrm{L} \mathrm{IBA}$, with $82.4 \%$ of rooting and 3.1 roots per plant. Dipping the shoots in IBA solution prior to culture media also allowed root development in up to 74\% of the shoots [16]. Oakes et al. developed a different approach for American chestnut, by testing the influence of light/darkness in the rooting process after IBA dipping and placing the shoots in semisolid medium [20]. Dark conditions produced $89 \%$ of rooted shoots compared to $67 \%$ of those kept in the light [20]. Sanchez et al. also improved their success rates to $80 \%$ in chestnut hybrids by placing the shoots in semisolid media with 3-mg/L IBA for 5 days in the dark [32]. However, the best number of roots per plant (7.4) was obtained by dipping the shoots in 1-g/L IBA [32]. Other approaches such as immersion systems are also proving to be successful by presenting rooting percentages up to $73 \%$ in hybrid chestnuts [34].

The highest rooting percentages were obtained using MMN, 90\% and 85\% for WPMZ and MSB elongations media, respectively. This suggests that MMN nutrient composition contributes for root development. MMN has many components thus, future research by testing them individually and also in different combinations, should provide us more information about the success during the rooting process. Furthermore, the wet-porous substrate should provide advantages on root development compared with common semisolid media, as observed for aerated substrates used in C. crenata [13], walnut hybrids and Australian shrubs propagation [35,36]. Tetsumura and Yamashita improved C. crenata rooting rates from $29 \%$ to $67 \%$, and number of roots per plant from 2 to 3.8 , by adding vermiculite to the semisolid medium [13].

The combination WPMZ + MMN showed a high number of roots per plant, indicating healthy and vigorous root morphology. In vitro induced root systems are usually different from those induced ex vitro, presenting a whitish surface $[5,33,37]$ and lacking branched roots and with a reduced number 
of root hairs [5]. This is a consequence of their anatomic physiognomy which has a poor differentiated vascular tissue [5] which can affect water and nutrient uptake and consequently reduce survival after acclimatization. Very often chestnut rooted plants do not survive when responding to ex vitro conditions [5,38-40]. Indeed, Gonçalves et al. improved the acclimatization survival in 50\% by rooting the shoots ex vitro instead of in vitro [5]. The combination WPMZ + MMN presented a high acclimatization rate, indicating that a functional root vascular system was developed.

\section{Conclusions}

The Portuguese chestnut breeding program benefits from a reliable tissue culture protocol that enables us to manage large scale vegetative propagation of chestnut. The proposed protocol is described in Figure 6 and includes the following steps: (1) maintenance of chestnut shoots in vitro in MSB medium for six weeks; (2) elongation with WPMZ for six weeks; (3) pre-rooting in the activated charcoal medium for seven days; (4) auxin hormonal shock with 1-g/L IBA for one minute, followed by placing the shoots into perlite:vermiculite (1:1) mixture wet with adapted MMN liquid medium for three weeks. Currently, other chestnut hybrids (C. sativa $\times$ C. crenata), C. sativa and C. crenata genotypes are being produced by this method at our laboratory for research and production purposes (NEW Cast Rootstocks-https://projects.iniav.pt/NewCastRootstocks).

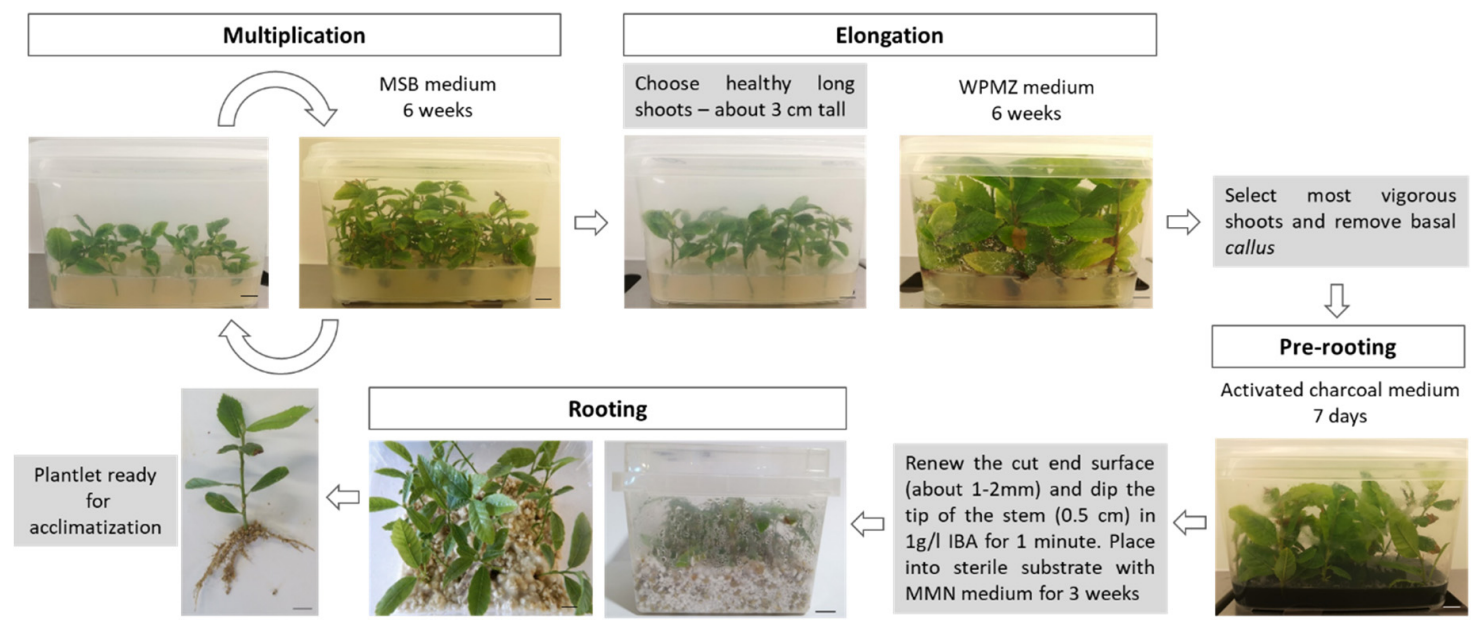

Figure 6. Schematic summary of the proposed protocol for hybrid chestnuts propagation. Bars $=1 \mathrm{~cm}$.

The continuous advances in chestnut breeding programs create the need to preserve and propagate valuable new genotypes. More chestnuts need to be produced every year for plantation and research purposes and overcoming the genotype-dependency, recalcitrance and the rooting bottleneck is paramount to the success of these programs. This protocol is a contribution to the existing body of knowledge.

Supplementary Materials: The following are available online at http://www.mdpi.com/1999-4907/11/8/826/s1, Figure S1: Rooting percentages of Castanea sativa $\times$ C. crenata hybrids (SC51, SC55, SC914, SC1202), C. sativa (CS12; Origin: TRAGSA, Spain) and C. crenata (CC14; Origin: TRAGSA, Spain) after rooting with adapted MMN liquid medium. Data correspond to the means of three rooting events $(n=40$ to 140 per rooting event). Bars correspond to standard error. Figure S2: Chestnut hybrids of SC1202 (A) and SC55 (B) genotypes (Castanea sativa $\times$ C. crenata) after two years in the field.

Author Contributions: Study concept and design: P.F., S.T. and R.L.C. Data collection: P.F., S.T., I.V.d.S., C.S., H.M. Statistical analysis: P.F. Interpretation of data: P.F., S.T., I.V.d.S., C.S., H.M. Drafting of the manuscript: P.F. Editing and critical revision of the manuscript: P.F., S.T., I.V.d.S., C.S., H.M., R.L.C. All authors have read and agreed to the published version of the manuscript.

Funding: This research was funded by Programa ProDer, Medida 4.1 Grant Number 53593 "Innovation in the production chain of chestnut: competitiveness and sustainability" Fundação para a.

Conflicts of Interest: The authors declare no conflict of interest. 


\section{References}

1. Vieitez, J.; Kingston, D.G.; Ballester, A.; Vieitez, E. Identification of two compounds correlated with lack of rooting capacity of chestnut cuttings. Tree Physiol. 1987, 3, 247-255. [CrossRef] [PubMed]

2. Vieitez, E. The Lack of Rootability of Chestnut Cuttings. In Proceedings of the Proceedings International Chestnut Conference; Double, M.L., MacDonald, W.L., Eds.; West Virginia University Press: Morgantown, WV, USA, 1992; pp. 82-88.

3. Pereira-Lorenzo, S.; Fernandez-Lopez, J. Propagation of chestnut cultivars by grafting: Methods, rootstocks and plant quality. J. Hortic. Sci. Biotechnol. 1997, 72, 731-739. [CrossRef]

4. Hardham, A.R. Phytophthora cinnamomi. Mol. Plant Pathol. 2005, 6, 589-604. [CrossRef] [PubMed]

5. Gonçalves, J.C.; Diogo, G.; Amâncio, S. In vitro propagation of chestnut (Castanea sativa $\times$ C. crenata): Effects of rooting treatments on plant survival, peroxidase activity and anatomical changes during adventitious root formation. Sci. Hortic. (Amsterdam) 1998, 72, 265-275. [CrossRef]

6. Breisch, H.; Boutitie, A.; Reyne, J.; Salesses, G.; Vaysse, P. Châtaignes et Marrons; FRA: Washington, DC, USA; CTIFL Centre Technique des Fruits et Légumes: Paris, France, 1995.

7. $\quad$ Burgess, T.I.; Scott, J.K.; Mcdougall, K.L.; Stukely, M.J.C.; Crane, C.; Dunstan, W.A.; Brigg, F.; Andjic, V.; White, D.; Rudman, T.; et al. Current and projected global distribution of Phytophthora cinnamomi, one of the world's worst plant pathogens. Glob. Chang. Biol. 2017, 23, 1661-1674. [CrossRef] [PubMed]

8. Costa, R.; Santos, C.; Tavares, F.; Machado, H.; Gomes-Laranjo, J.; Kubisiak, T.; Nelson, C. Mapping and transcriptomic approches implemented for understanding disease resistance to Phytophthora cinammomi in Castanea sp. BMC Proc. 2011, 5, O18. [CrossRef]

9. Santos, C.; Machado, H.; Correia, I.; Gomes, F.; Gomes-Laranjo, J.; Costa, R. Phenotyping Castanea hybrids for Phytophthora cinnamomi resistance. Plant Pathol. 2015, 64, 901-910. [CrossRef]

10. Sánchez, M.; Ballester, A.; Vieitez, A. Reinvigoration treatments for the micropropagation of mature chestnut trees. Ann. Sci. For. 1997, 54, 359-370. [CrossRef]

11. Giovannelli, A.; Giannini, R. Reinvigoration of mature chestnut (Castanea sativa) by repeated graftings and micropropagation. Tree Physiol. 2000, 20, 1243-1248. [CrossRef]

12. Ballester, A.; Bourrain, L.; Corredoira, E.; Gonçalves, J.C.; Lê, C.-L.; Miranda-Fontaína, E.; San-josé, M.C.; Sauer, U.; Vieitez, A.M.; Wilhelm, E. Improving chestnut micropropagation through axillary shoot development and somatic embryogenesis. For. Snow Landsc. Res. 2001, 76, 460-467.

13. Tetsumura, T.; Yamashita, K. Micropropagation of Japanese chestnut (Castanea crenata Sieb. et Zucc.) seedlings. HortScience 2004, 39, 1684-1687. [CrossRef]

14. Oakes, A.; Desmarais, T.; Powell, W.A.; Maynard, C.A. Improving Rooting and Shoot Tip Survival of Micropropagated Transgenic American Chestnut Shoots. HortScience 2016, 51, 171-176. [CrossRef]

15. Vieitez, A.M.; Sánchez, C.; San-José, C. Prevention of shoot-tip necrosis in shoot cultures of chestnut and oak. Sci. Hortic. (Amsterdam) 1989, 41, 151-159. [CrossRef]

16. Gonçalves, J.C.; Amâncio, S.; Pereira, J.S. Rooting and acclimatization of chestnut by in vitro propagation. In Physiology, Growth and Development of Plants in Culture; Lumdsen, P.J., Nicholas, J.R., Davies, W.J., Eds.; Kluwer Acad. Pub.: Dordrecht, The Netherlands, 1994; pp. 303-308.

17. Vieitez, E.; Vieitez, A. Juvenility factors related to the rootability of chestnut cuttings. Acta Hortic. 1976, 269-274. [CrossRef]

18. Ballester, A.; San-José, M.C.; Vidal, N.; Fernández-Lorenzo, J.L.; Vieitez, A.M. Anatomical and Biochemical Events during in vitro Rooting of Microcuttings from Juvenile and Mature Phases of Chestnut. Ann. Bot. 1999, 83, 619-629. [CrossRef]

19. Lê, C.-L. Factors influencing in vitro rooting of chestnut. For. Snow Landsc. Res. 2001, 76, 468-470.

20. Oakes, A.D.; Powell, W.A.; Maynard, C.A. Doubling Acclimatization Survival of Micropropagated American Chestnuts with Darkness and Shortened Rooting Induction Time. J. Environ. Hort. 2013, 31, 77-83.

21. Seabra, R.C.; Pais, M.S. Micropropagação de Clones de Castanheiro (Castanea sativa Mill.) Resistentes à doença da tinta. Silva Lusit. 1993, 1, 169-181.

22. Santos, C.; Duarte, S.; Tedesco, S.; Fevereiro, P.; Costa, R.L. Expression profiling of Castanea genes during resistant and susceptible interactions with the oomycete pathogen Phytophthora cinnamomi reveal possible mechanisms of immunity. Front. Plant Sci. 2017, 8, 515. [CrossRef] 
23. Murashige, T.; Skoog, F. A Revised Medium for Rapid Growth and Bio Assays with Tobacco Tissue Cultures. Physiol. Plant. 1962, 15, 473-497. [CrossRef]

24. Lloyd, G.; McCown, B. Commercially feasible micropropagation of mountain laurel, (Kalmia latifolia) by use of shoot tip culture. Comb. Proc. Int. Plant Propagators' Soc. 1980, 30, 421-427.

25. Marx, D.H. The influence of ectotrophic mycorrhizal fungi on the resistance of pine roots to pathogenic infections. II. Production, identification, and biological activity of antibiotics produced by Leucopaxillus cerealis var. piceina. Phytopathology 1969, 59, 411-417. [PubMed]

26. Feijó, J.A.; Pais, M.S.S. Rejuvenation of Adult Specimens of Castanea Sativa Mill: Through In Vitro Micropropagation. In Plant Aging: Basic and Applied Approaches.; Rodrigues, R., Sánchez Tamés, R., Durzan, D., Eds.; Plenum Press: New York, NY, USA, 1990; pp. 383-387.

27. Ballester, A.; Sanchez, M.C.; Vieitez, A.M. Etiolation as a pretreatment for in vitro establishment and multiplication of mature chestnut. Physiol. Plant. 1989, 77, 395-400. [CrossRef]

28. Thomas, T.D. The role of activated charcoal in plant tissue culture. Biotechnol. Adv. 2008, 26, 618-631. [CrossRef] [PubMed]

29. Beyl, C.A. Getting Started with Tissue Culture: Media Preparation, Sterile Technique, and Laboratory Equipment. In Plant Propagation Concepts and Laboratory Exercises; Beyl, C.A., Trigiano, R.N., Eds.; CRC Press: Boca Raton, FL, USA, 2015; pp. 371-384.

30. Woodward, S.; Thomson, R.J. Micropropagation of the silk tassel bush, Garrya elliptica Dougl. Plant Cell. Tissue Organ Cult. 1996, 44, 31-35. [CrossRef]

31. Makunga, N.P.; Van Staden, J. An efficient system for the production of clonal plantlets of the medicinally important aromatic plant: Salvia africana-lutea L. Plant Cell. Tissue Organ Cult. 2008, 92, 63-72. [CrossRef]

32. Sanchez, M.C.; San-jose, M.C.; Ferro, E.; Ballester, A.; Vieitez, A.M. Improving micropropagation conditions for adult- phase shoots of chestnut. J. Hortic. Sci. 1997, 72, 433-443. [CrossRef]

33. Xing, Z.; Satchwell, M.F.; Powell, W.A.; Maynard, C.A. Micropropagation of american chestnut: Increasing rooting rate and preventing shoot-Tip necrosis. Vitr. Cell. Dev. Biol.-Plant 1997, 33, 43-48. [CrossRef]

34. Cuenca, B.; Sánchez, C.; Aldrey, A.; Bogo, B.; Blanco, B.; Correa, B.; Vidal, N. Micropropagation of axillary shoots of hybrid chestnut (Castanea sativa $\times$ C. crenata) in liquid medium in a continuous immersion system. Plant Cell Tissue Organ Cult. 2017, 131, 307-320. [CrossRef]

35. Jay-Allemand, C.; Capelli, P.; Cornu, D. Root development of in vitro hybrid walnut microcuttings in a vermiculite-containing gelrite medium. Sci. Hortic. (Amsterdam) 1992, 51, 335-342. [CrossRef]

36. Newell, C.; Growns, D.; McComb, J. The influence of medium aeration on in vitro rooting of Australian plant microcuttings. Plant Cell. Tissue Organ Cult. 2003, 75, 131-142. [CrossRef]

37. Corredoira, E.; Martínez, M.; Cernadas, M.; San José, M. Application of Biotechnology in the Conservation of the Genus Castanea. Forests 2017, 8, 394. [CrossRef]

38. Vieitez, A.M.; Sänchez, M.C.; García-Nimo, M.L.; Ballester, A. Protocol for Micropropagation of Castanea sativa. In Protocols for Micropropagation of Woody Trees and Fruits; Springer: Dordrecht, The Netherlands, 2007; pp. 299-312.

39. Carvalho, L.; Amâncio, S. Effect of ex vitro conditions on growth and acquisition of autotrophic behaviour during the acclimatisation of chestnut regenerated in vitro. Sci. Hortic. (Amsterdam) 2002, 95, 151-164. [CrossRef]

40. Sáez, P.L.; Bravo, L.A.; Latsague, M.I.; Toneatti, M.J.; Coopman, R.E.; Álvarez, C.E.; Sánchez-Olate, M.; Ríos, D.G. Influence of in vitro growth conditions on the photosynthesis and survival of Castanea sativa plantlets during ex vitro transfer. Plant Growth Regul. 2015, 75, 625-639. [CrossRef]

(C) 2020 by the authors. Licensee MDPI, Basel, Switzerland. This article is an open access article distributed under the terms and conditions of the Creative Commons Attribution (CC BY) license (http://creativecommons.org/licenses/by/4.0/). 